\title{
Impact of opioid dose reduction on individuals with chronic pain: results of an online survey
}

\author{
This article was published in the following Dove Press journal:
} Journal of Pain Research

\author{
Robert K Twillman ${ }^{1,2}$ \\ Nicole Hemmenway ${ }^{3}$ \\ Steven D Passik ${ }^{4}$ \\ Christy A Thompson ${ }^{4}$ \\ Michael Shrum ${ }^{4}$ \\ Michael K DeGeorge ${ }^{4}$ \\ 'Academy of Integrative Pain \\ Management, Lenexa, KS, USA; \\ ${ }^{2}$ Department of Psychiatry and \\ Behavioral Sciences, University of \\ Kansas School of Medicine, Kansas \\ City, KS, USA; ${ }^{3}$ US Pain Foundation, \\ Middletown, CT, USA; ${ }^{4}$ Collegium \\ Pharmaceutical Inc., Canton, MA, USA
}

Correspondence: Robert K Twillman Academy of Integrative Pain Management, 8700 Monrovia Street, Suite 310, Lenexa, KS 66215 , USA

Tel +l 2098132165

Email btwillman@integrativepain.org
Background: In 2016, the Centers for Disease Control and Prevention (CDC) released a guideline on opioid prescribing for primary care physicians. Patients with chronic pain receiving long-term opioid therapy were surveyed to assess the incidence and impact of opioid dose reduction following this guideline's promulgation.

Methods: Members of an advocacy organization for people with chronic pain were invited to participate in a 16-item, anonymous, online survey conducted in September/October 2017. Eligibility requirements included current treatment of $\geq 7$ months' duration for chronic pain with the same extended-release (ER)/long-acting (LA) opioid. The final sample consisted of respondents who reported being on the same ER/LA opioid for $\geq 1$ year and excluded respondents whose 1) ER/LA opioid dose increased; 2) ER/LA opioid dose decreased and immediate-release (IR) opioid dose increased; and 3) ER/LA opioid dose was unchanged and IR opioid dose was changed. Survey results were analyzed using $z$-test to ascertain differences between proportion of responses for ER/LA opioid dose decreased vs dose unchanged groups.

Results: Of the 511 eligible respondents, 362 respondents were included in the final sample. In the final sample, the subgroup with decreased ER/LA opioid dose $(n=149)$ was significantly more likely $(P \leq 0.05)$ than those who reported no dose change $(n=213)$ to rate their condition as "worse" for level of pain (73.2 vs $33.3 \%$ ), level of function (67.8 vs $31.5 \%$ ), mental health ( 64.4 vs $32.9 \%$ ), ability to work ( $62.9 \%$ of 97 respondents vs $33.8 \%$ of 145 respondents), and interpersonal relationships ( 48.3 vs $25.8 \%$ ) during the previous 6 months.

Conclusion: In this Internet-based survey of people with chronic pain, reduction of ER/LA opioid dose was associated with reduced pain control and diminished function. These results indicate a need for further guidance on how to apply the CDC guideline to patients with chronic pain who are stable on long-term opioid therapy.

Keywords: CDC guideline, chronic pain, long-term opioid therapy, survey

\section{Plain language summary}

This article reports the results of an online survey of people with chronic pain who were being treated with an extended-release (ER)/long-acting (LA) opioid medication. A total of 511 people with chronic pain completed the survey, 362 of whom met criteria to be included in the final sample. In this group of 362 people, 149 respondents reported that their dose of ER/LA opioid medication had been decreased during the past 6 months and 213 respondents reported unchanged doses. Respondents whose ER/LA opioid medication dose was decreased were more likely than respondents with no change in dose to report worsening in many aspects of life, including amount of pain, level of function, mental health, ability to work, and relationships with other people. Among patients receiving long-term treatment for chronic pain with opioids in this survey population, decreasing the ER/LA opioid dose was associated with increased levels of pain and decreased ability to function. 


\section{Introduction}

Chronic pain affects more than 100 million Americans and can be debilitating, causing marked impairment in health status, quality of life, work, personal relationships, mental health, and daily activities. ${ }^{1-5}$ Opioid analgesics are a common treatment option for people with chronic pain. ${ }^{6}$ Although no data are available specifically for chronic pain, the annual opioid prescribing rate in the United States was 66.5 prescriptions per 100 persons in $2016 .^{7}$ Responsible opioid prescribing dictates that providers evaluate both the expected benefits (eg, optimal pain control and function) and risks (eg, adverse events, potential for misuse/abuse) of long-term use. ${ }^{8}$ Currently, the United States is experiencing an opioid overdose epidemic. ${ }^{9}$ In 2016, more than 42,000 overdose deaths were associated with opioids, including natural (eg, morphine) and semisynthetic (eg, oxycodone, hydrocodone) prescription opioids, synthetic opioids (eg, fentanyl; primarily illicitly produced), and heroin. Consequently, attention has increasingly focused on the risks rather than on the potential benefits of chronic opioid therapy. However, in light of the prevalence and burden of chronic pain, ${ }^{1,4}$ it is important that these treatments remain available to patients.

The 2016 Centers for Disease Control and Prevention (CDC) guideline on opioid prescribing suggests that clinicians "should use caution when prescribing opioids at any dosage, should carefully reassess the evidence of individual benefits and risks when considering increasing dosage to $\geq 50$ morphine milligram equivalents (MME)/day, and should avoid increasing dosage to $\geq 90 \mathrm{MME} /$ day or carefully justify a decision to titrate dosage to $\geq 90 \mathrm{MME} /$ day." ${ }^{10}$ These recommendations are presented as "voluntary, rather than prescriptive standards," and the guideline asserts that "clinical decision-making should be based on a relationship between the clinician and patient and an understanding of the patient's clinical situation, functioning, and life context." ${ }^{\prime 10}$

The American Medical Association (AMA) has expressed concerns about the $\mathrm{CDC}$ guideline, ${ }^{11}$ including the potential for insurers and other payers to consider guideline recommendations as inflexible rules, rather than points for prescribers to consider, and use the recommendations to deny coverage. The guideline recommendations also may be used by pharmacies to deny prescriptions that exceed the recommended thresholds. State medical board opioid guidelines (eg, guidelines from the Federation of State Medical Boards) ${ }^{12}$ discourage clinicians from prescribing opioid dosages higher than the CDC guideline thresholds, and some payer policies ${ }^{13}$ link the guideline to supply limits for opioids in the treatment of chronic noncancer pain. As a result, the guideline may have unintended consequences of not only creating barriers to initial prescription but also disrupting care in otherwise stable patients, ${ }^{14}$ even though the guideline itself notes that the dosing recommendations are less applicable to established patients already receiving long-term opioid therapy. ${ }^{10}$ Furthermore, reports from patients and health care providers corroborate the concerns about CDC guidelines expressed by the AMA. ${ }^{15,16}$

The objective of this study, which was conducted after the publication of the CDC guidelines, was to assess the incidence and impact of opioid dose reduction on patients with chronic pain receiving long-term opioid therapy.

\section{Participants and methods Participants}

This study was conducted as a collaboration between the US Pain Foundation (a not-for-profit patient advocacy group) and Collegium Pharmaceutical. Participants were members of the US Pain Foundation who were recruited for the study; the organization's membership numbered more than 90,000 as of January 2017. All members were sent an email inviting them to participate in a survey about recent changes that may have been made to their chronic pain treatment. One reminder email was sent. Eligibility, based on current medical professional-directed treatment of $\geq 7$ months' duration for chronic pain, including treatment with the same extended-release (ER)/long-acting (LA) opioid medication for $\geq 7$ months, was determined with screening questions. Eligible respondents provided consent to participate before answering survey questions, and they were enabled to participate in the survey anonymously. No incentives or compensation was offered for survey participation. This study was exempted from institutional review board (IRB) approval by IntegReview IRB, Austin, TX, USA, based on the exemption of research involving anonymous survey procedures (IRB exemption category 2 ).

\section{Survey design}

The 16-item, online questionnaire (administered using Survey Monkey from September 25 to October 17, 2017), which inquired about opioid medications, pain severity, level of function, and side effects during the previous 6 months, was designed specifically for this study (Supplementary materials). The side effects queried in the survey included those associated with opioid use (ie, constipation, dizziness, drowsiness, headache, itching, nausea, and vomiting) and opioid withdrawal (ie, chills, dilated pupils, muscle pain, restlessness, runny nose, sweating, teary eyes, and yawning). 


\section{Statistical analyses}

Data were imported into the MarketSight ${ }^{\mathrm{TM}}$ (MarketSight LLC, Newton, MA, USA) analysis software program and summarized using descriptive statistics. To reliably assess the impact of daily ER/LA opioid dose reduction on pain severity, level of function, and side effects, the final sample included respondents who reported being on the same ER/LA opioid for $\geq 1$ year and excluded respondents whose 1) ER/ LA opioid dose increased; 2) ER/LA opioid dose decreased and immediate-release (IR) opioid dose increased; and 3) ER/ LA opioid dose had not changed and IR opioid dose changed (decreased or increased). Between-group differences were assessed for statistical significance $(P \leq 0.05)$ using $z$-test to ascertain differences between the proportion of responses for the ER/LA opioid dose decreased vs dose unchanged groups. An alternate test, the Fisher's exact test, was used to ascertain differences between the proportion of responses for these groups when the number of responses was low.

\section{Results}

\section{Opioid therapy}

Of the 11,504 email invitations sent to people to participate in the survey, 1,829 people responded (15.9\% survey response rate). A total of 511 respondents met selection criteria (all respondents; Figure 1); 93.3\% reported receiving chronic pain treatment directed by a medical professional for more than 1 year and $6.7 \%$ had received treatment for 7 months to 1 year. Duration of treatment with an ER/LA opioid was $>1$ year in $91.0 \%$ of respondents and 7 months to 1 year in the remaining $9.0 \%$ of respondents. Most respondents (76.9\%) were also prescribed an IR opioid medication. Approximately one-third of all respondents (32.3\%) reported that their ER/ LA opioid dose had been decreased in the past 6 months; 13.7 and $54.0 \%$ reported that their dose was increased or remained unchanged, respectively.

Of the 362 respondents meeting the inclusion criteria for the final sample (Figure 1), 149 and 213 respondents reported that their ER/LA dose was decreased and unchanged, respectively. Similar proportions of respondents in the ER/LA dose decreased and unchanged subgroups reported concomitant IR opioid therapy ( 73.8 and $76.1 \%$, respectively). Significantly greater proportions of the ER/LA opioid dose decreased group (50.3\%) reported the addition of a new medication in the previous 6 months compared with the unchanged ER/LA opioid dose group (37.6\%) in the final sample.

\section{Pain and function}

All respondents' ratings of change in the level of pain, function, interpersonal relationships, and mental health during the previous 6 months are summarized in Figure 2. Across all items, respondents in the final sample reporting decreased ER/LA dose were significantly more likely $(P \leq 0.05)$ to rate their condition as "worse" than those who reported no ER/ LA dose change (Figure 3).

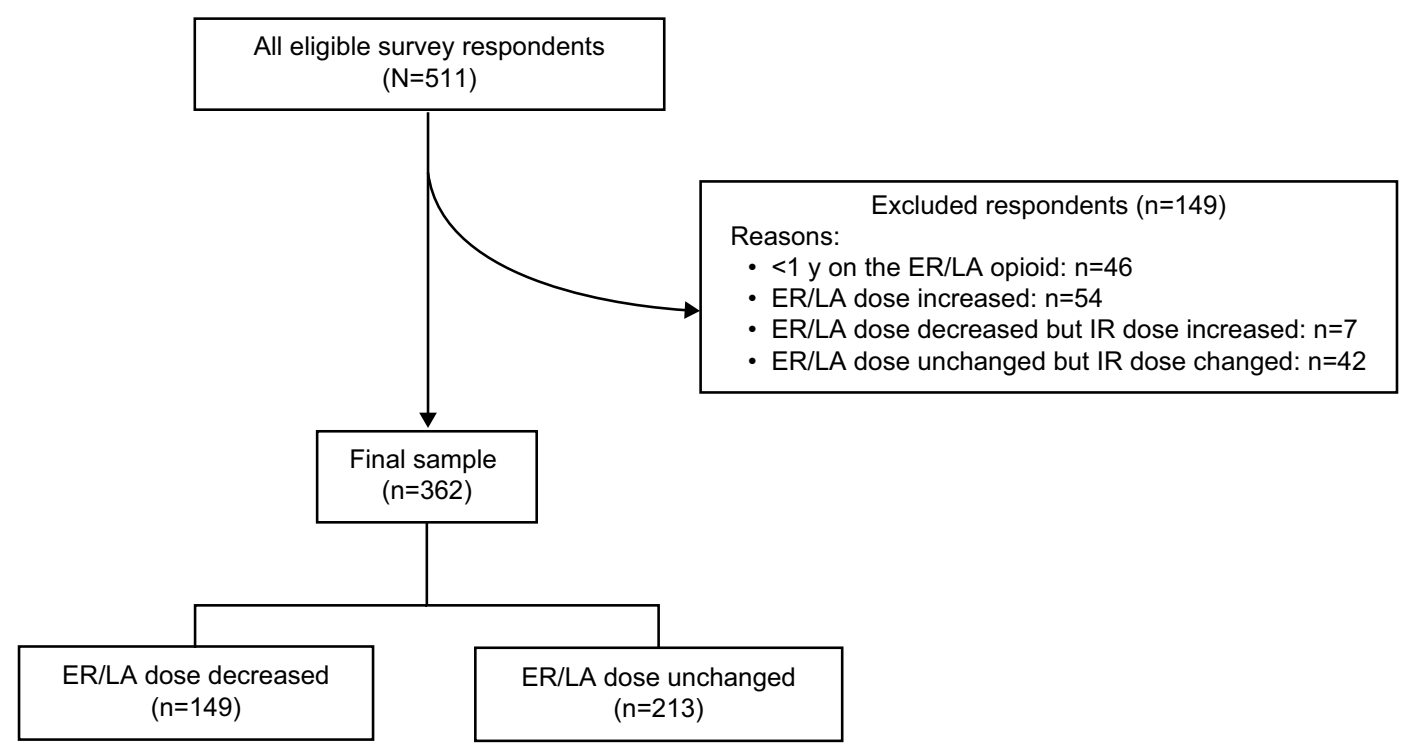

Figure I Study flow diagram.

Abbreviations: ER, extended-release; LA, long-acting. 


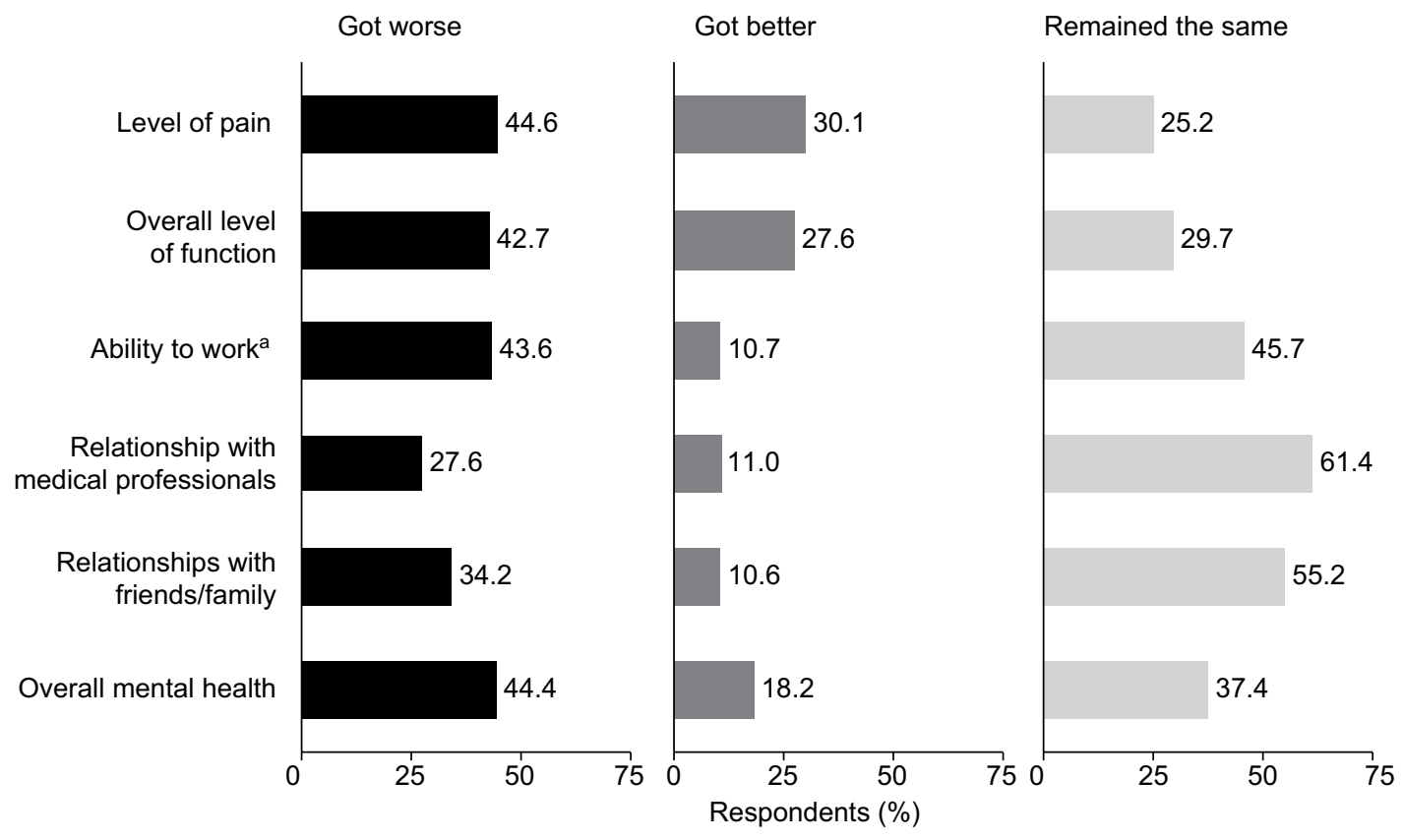

Figure 2 Pain and function during the previous 6 months among all eligible respondents $(\mathrm{N}=5 \mathrm{I} \mathrm{I})$.

Note: ${ }^{a} n=346$, excluding respondents who answered "not applicable" to this question (eg, retired).

\section{Adverse events}

Respondents whose ER/LA opioid dose was decreased were more likely ( $P \leq 0.05$ for each) to report increases in the frequency of adverse events associated with opioid withdrawal for seven of the eight listed types of events (Table 1) in the past 6 months, which were muscle pain, sweating, restlessness, chills, runny nose, teary eyes, and yawning.

\section{Discussion}

In this Internet-based survey of people with chronic pain, more than $90 \%$ of the study participants reported receiving chronic pain treatment directed by a medical professional for longer than 1 year. One-third of respondents reported a decrease in ER/LA opioid dose during the previous 6 months; the decrease in medication dosing was associated with reduced pain control and negative impact on function, interpersonal relationships, and mental health. Respondents whose ER/LA opioid dose was decreased were more likely to report increases in adverse events associated with opioid withdrawal compared with those whose dose was unchanged.

The findings of the current survey are consistent with those reported by the Pain News Network following its survey of patients $(\mathrm{N}=3,108)$ and health care providers $(\mathrm{N}=278)$, which was conducted in collaboration with the
International Pain Foundation between February 15 and March 11, 2017 (following the CDC dosing guideline release). Approximately $48 \%$ of patients reported a decrease in opioid dose, $23 \%$ reported the discontinuation of opioid medication, and $84 \%$ reported worsened pain. ${ }^{15}$ More than one-half $(59 \%)$ of health care providers reported that a pharmacy had refused to fill an opioid prescription, and $57 \%$ reported that an insurance company had refused to pay for a pain treatment the provider thought the patient should have. Recent changes in opioid prescribing are also evident in retail prescription trends. ${ }^{16}$ Together, these findings suggest that unintended consequences of the opioid dose reduction guidelines may include not only barriers to initial prescribing but also disruption of care in patients taking stable ER/LA opioid doses. Such an outcome may violate the core tenets of opioid prescribing - including those in the CDC guideline itself - which mandates patient-centric care. ${ }^{17}$ These unintended consequences may also extend to a recently reported sharp increase in emergency department admissions for nonfatal opioid overdoses. ${ }^{18}$ In an attempt to mitigate observed untoward consequences, Canada has issued updated opioid prescribing guidelines that provide clinicians with more detailed guidance on opioid tapering, including a clear statement that tapers may be abandoned under certain circumstances. ${ }^{19}$ 
A

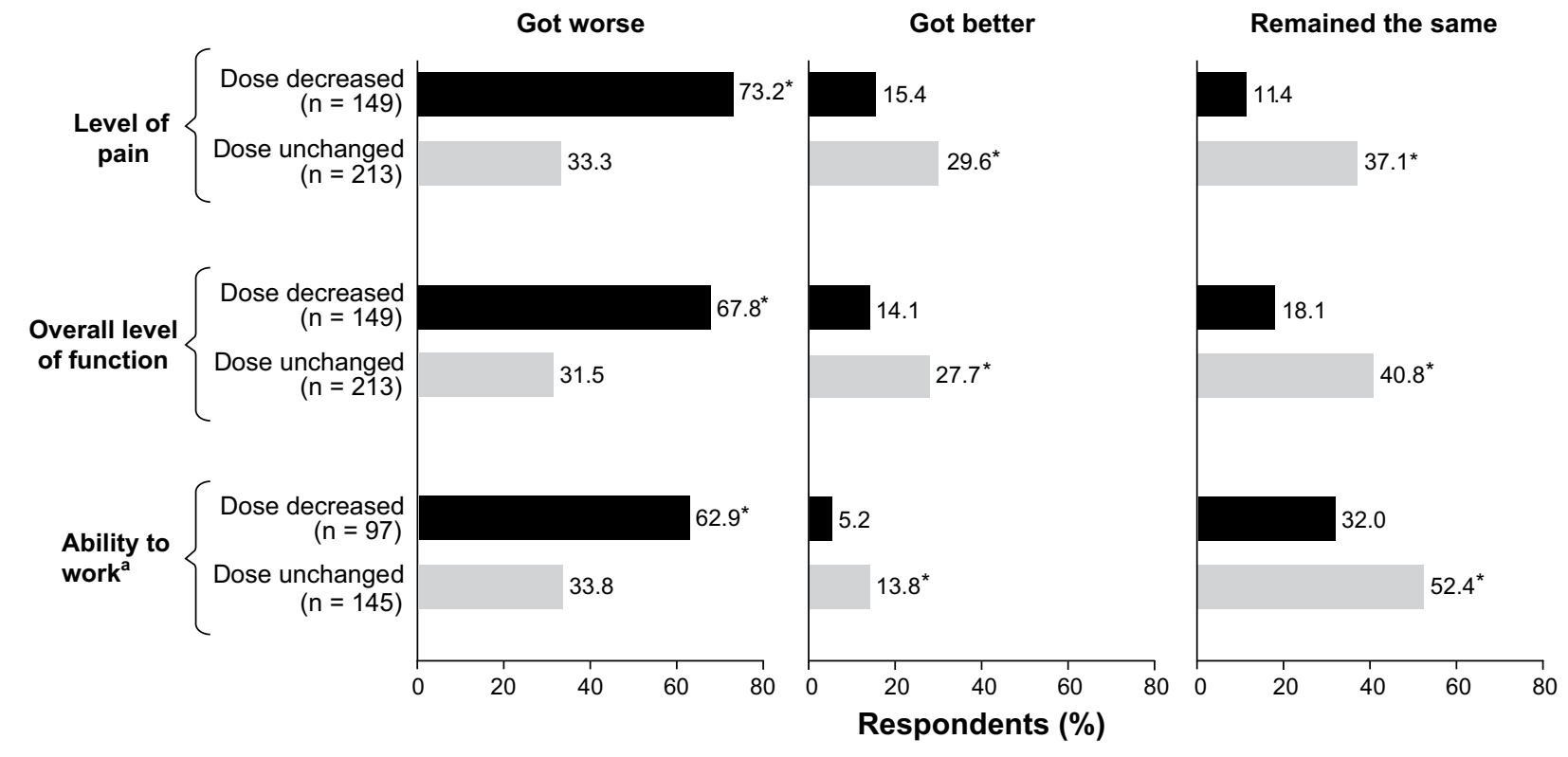

B
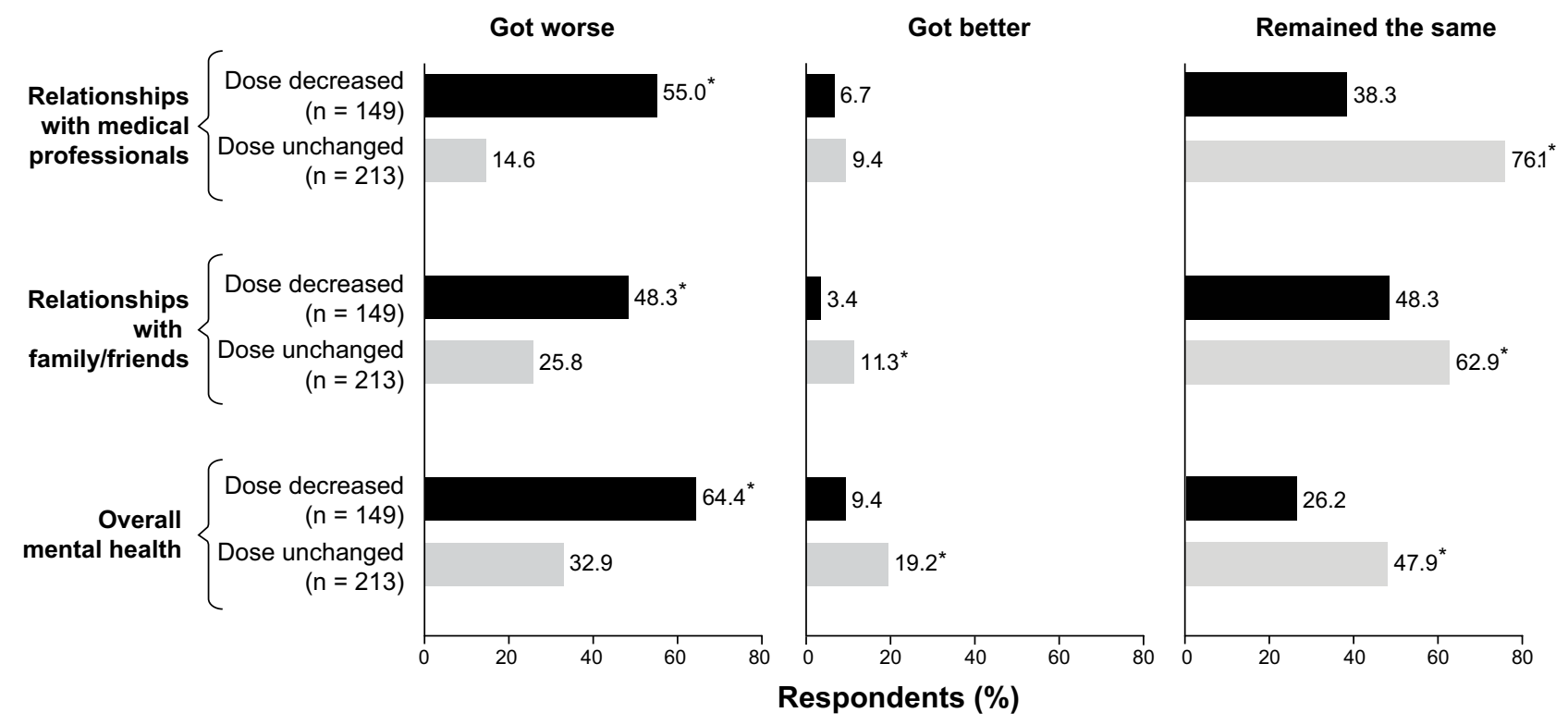

Figure 3 Final sample population perception of pain and function during the previous 6 months, by change in ER/LA opioid dose (A) level of pain, overall function, and ability to work and (B) interpersonal relationships and mental health.

Notes: "Excluding patients who responded "not applicable" to this question (eg, retired). *Percentage shown is significantly greater ( $P \leq 0.05)$ than the percentage for the corresponding response (ie, got worse, got better, and remained the same) in the other group based on z-test.

Abbreviations: ER, extended-release; LA, long-acting.

There is inadequate evidence or justification to arbitrarily limit doses in patients adequately assessed and monitored with risk management tools to minimize the risk of opioid misuse/abuse (eg, ongoing monitoring for aberrant drugtaking behaviors, use of abuse-deterrent opioid formulations). ${ }^{17,20} \mathrm{~A}$ study of voluntary opioid tapering in patients at a community clinic who were taking high-dose opioids (median MME: $288 \mathrm{mg}$ tapered to $150 \mathrm{mg}$ in 4 months) for chronic noncancer pain showed that although there was no worsening of pain among completers, there was a high dropout rate (37.8\%). ${ }^{21}$ In addition, despite the reduction in high-dose opioid prescriptions in the United States (46.5\% reduction from 2010 to 2016), opioid overdose-related mortality has not declined during this period. ${ }^{7,22}$ Therefore, astute clinicians can incorporate the dose thresholds suggested by the guidelines into their regular opioid prescribing protocols 
Table I Percentage of respondents reporting that adverse events occurred more frequently or less frequently, by change in daily ER/ LA opioid dose ${ }^{\mathrm{a}}$

\begin{tabular}{|c|c|c|c|c|}
\hline \multirow[t]{2}{*}{ AEs, \% ${ }^{\mathrm{b}}$} & \multicolumn{2}{|l|}{ More Frequent } & \multicolumn{2}{|l|}{ Less Frequent } \\
\hline & $\begin{array}{l}\text { Dose Decreased } \\
(n=\mid 49)\end{array}$ & $\begin{array}{l}\text { Dose Unchanged } \\
(n=2 \mid 3)\end{array}$ & $\begin{array}{l}\text { Dose Decreased } \\
(n=\mid 49)\end{array}$ & $\begin{array}{l}\text { Dose Unchanged } \\
(n=2 \mid 3)\end{array}$ \\
\hline \multicolumn{5}{|c|}{ Common AEs associated with opioid use } \\
\hline Headache & $54.4^{*}$ & 20.2 & 3.4 & 5.6 \\
\hline Nausea & $34.2^{*}$ & 14.1 & 1.3 & 5.2 \\
\hline Dizziness & $24.8^{*}$ & 16.0 & 4.0 & 2.8 \\
\hline Drowsiness & $23.5^{*}$ & 15.0 & 5.4 & 7.0 \\
\hline Constipation & 16.8 & 23.5 & 10.1 & 8.5 \\
\hline Vomiting & $15.4^{*}$ & 2.8 & 0.7 & 2.3 \\
\hline Itching & 12.8 & 15.5 & 2.0 & 2.3 \\
\hline \multicolumn{5}{|c|}{ AEs associated with opioid withdrawal } \\
\hline Muscle pain & $70.5^{*}$ & 34.3 & 5.4 & 11.3 \\
\hline Sweating & $47.7^{*}$ & 21.1 & 2.0 & 6.1 \\
\hline Restlessness & $54.4^{*}$ & 19.7 & 2.7 & 4.2 \\
\hline Chills & $29.5^{*}$ & 10.3 & 0.7 & 3.3 \\
\hline Runny nose & $28.2^{*}$ & 11.3 & 0.7 & 0 \\
\hline Teary eyes & $26.2^{*}$ & 11.7 & 2.7 & 1.9 \\
\hline Yawning & $23.5^{*}$ & 11.7 & 3.4 & 2.3 \\
\hline Dilated pupils & 5.4 & 2.3 & $2.7 * *$ & 0 \\
\hline
\end{tabular}

Notes: a During the previous 6 months in the final sample population. ${ }^{b}$ Data shown as percentage of respondents. "Significantly greater response $(P \leq 0.05)$ compared with ER/ LA dose unchanged group for the corresponding response (more frequent) based on z-test. "Significantly greater response ( $P \leq 0.05)$ compared with ER/LA dose unchanged group for the corresponding response (less frequent) based on Fisher's Exact test.

Abbreviations: AE, adverse event; ER/LA, extended-release/long-acting.

but use them as opportunities to reevaluate benefits and harms of ongoing therapy in individual patients. ${ }^{23,24}$

The results of this study must be interpreted carefully, considering its limitations, including recruitment from the membership of a patient advocacy organization that may not be representative of the general chronic pain population. Lack of available demographic information complicates generalization to a broader population. Potential variability in changes in prescribing practices by region cannot be ruled out, as geographic information was not collected in this survey. Motivation for opioid dose changes was not sought; thus, reported opioid dose changes may have been driven by patient-specific factors independent of the CDC guideline. Additionally, as patient reports of the magnitude of opioid dose changes are not reliable, this information was not collected. All information was provided by survey respondents and not verified by health care providers. The assessment of changes in pain severity, level of function, and mental health was based on self-reporting by the patient instead of the use of a validated tool.

\section{Conclusion}

In this Internet-based survey of people with chronic pain that was conducted after the publication of the CDC guideline for opioid prescribing, decreases in opioid dose were associated with reduced pain control and diminished function. These results demonstrate a need for further guidance on how to apply the CDC guideline to patients with chronic pain who are stable on long-term opioid therapy.

\section{Acknowledgments}

The authors thank Paul Gileno, US Pain Foundation, Middletown, CT, USA, for providing support with the development and implementation of the survey that provided the data for this article. Technical editorial and medical writing assistance was provided by Nancy Holland, PhD, and Mary Tom, PharmD, for Synchrony Medical Communications, LLC, West Chester, PA, USA, under the direction of authors. Funding for this support was provided by Collegium Pharmaceutical, Inc., Canton, MA, USA.

\section{Disclosure}

RKT reports serving as a consultant to Millennium Health. SDP, CAT, MS, and MKD are employees of Collegium Pharmaceutical, Inc. NH reports no conflicts of interest in this work.

\section{References}

1. Institute of Medicine (US) Committee on Advancing Pain Research Care and Education. Relieving Pain in America: A Blueprint for Transforming Prevention, Care, Education, and Research. Washington, DC: The National Academies Press; 2011.

2. Nahin RL. Estimates of pain prevalence and severity in adults: United States, 2012. J Pain. 2015;16(8):769-780. 
3. Johannes CB, Le TK, Zhou X, Johnston JA, Dworkin RH. The prevalence of chronic pain in United States adults: results of an Internet-based survey. J Pain. 2010;11(11):1230-1239.

4. Breivik H, Eisenberg E, O'Brien T; OPENMinds. The individual and societal burden of chronic pain in Europe: the case for strategic prioritisation and action to improve knowledge and availability of appropriate care. BMC Public Health. 2013;13:1229.

5. Phillips CJ. The cost and burden of chronic pain. Rev Pain. 2009;3(1):2-5.

6. Lembke A, Humphreys K, Newmark J. Weighing the risks and benefits of chronic opioid therapy. Am Fam Physician. 2016;93(12):982-990.

7. Centers for Disease Control and Prevention. Annual Surveillance Report of Drug-Related Risks and Outcomes:United States, 2017. Atlanta, Georgia: Centers for Disease Control and Prevention; 2017.

8. Chou R, Fanciullo GJ, Fine P, et al; American Pain Society-American Academy of Pain Medicine Opioids Guidelines Panel. Clinical guidelines for the use of chronic opioid therapy in chronic noncancer pain. J Pain. 2009; 10(2):113-130.

9. Centers for Disease Control and Prevention [webpage on the Internet] Opioid Overdose Page. Available from: https://www.cdc.gov/drugoverdose/index.html. Accessed May 18, 2018.

10. Dowell D, Haegerich TM, Chou R. CDC Guideline for Prescribing Opioids for Chronic Pain - United States, 2016. MMWR Recomm Rep. 2016;65(1):1-49.

11. Harris PA. The opioid epidemic: AMA's response. Am Fam Physician. 2016;93(12):975.

12. Federation of State Medical Boards. Guidelines for the Chronic Use of Opioid Analgesics. 2017. Available from: https://www.fsmb.org/ globalassets/advocacy/policies/opioid_guidelines_as_adopted_april2017_final.pdf. Accessed May 18, 2018.

13. United Healthcare. Opioid Overutilization Prevention and Opioid Use Disorder Treatment Programs for United Healthcare Commercial Plans Quick Reference Guide; 2018. Available from: https:/www.uhcprovider. com/content/dam/provider/docs/public/resources/pharmacy/OpioidOverutilization-Prevention-QRG.pdf. Accessed May 18, 2018.
14. Anson P [webpage on the Internet]. Survey: Opioids Reduced or Stopped for Most Patients; 2018. Available from: https://www.painnewsnetwork. org/stories/2016/8/4/survey-opioids-stopped-or-reduced-for-mostpatients. Accessed May 18, 2018.

15. Pain News Network [webpage on the Internet]. 2017 CDC Survey Results; 2018. Available from: https://www.painnewsnetwork.org/2017cdc-survey. Accessed May 18, 2018.

16. Guy GP Jr, Zhang K, Bohm MK, et al. Vital signs: changes in opioid prescribing in the United States, 2006-2015. MMWR Morb Mortal Wkly Rep. 2017;66(26):697-704.

17. Passik SD. Issues in long-term opioid therapy: unmet needs, risks, and solutions. Mayo Clin Proc. 2009;84(7):593-601.

18. Vivolo-Kantor AM, Seth P, Gladden RM, et al. Vital signs: trends in emergency department visits for suspected opioid overdoses - United States, July 2016-September 2017. MMWR Morb Mortal Wkly Rep. 2018;67(9):279-285.

19. Busse JW, Craigie S, Juurlink DN, et al. Guideline for opioid therapy and chronic noncancer pain. CMAJ. 2017;189(18):E659-E666.

20. Hale ME, Moe D, Bond M, Gasior M, Malamut R. Abuse-deterrent formulations of prescription opioid analgesics in the management of chronic noncancer pain. Pain Manag. 2016;6(5):497-508.

21. Darnall BD, Ziadni MS, Stieg RL, Mackey IG, Kao MC, Flood P. Patient-centered prescription opioid tapering in community outpatients with chronic pain. JAMA Intern Med. 2018:1-2.

22. Kertesz SG. Turning the tide or riptide? The changing opioid epidemic. Subst Abus. 2017;38(1):3-8.

23. Passik SD, Heit HA, DeGeorge M. Reality and responsibility revisited: Stakeholder accountability in the effort to develop safer opioids. J Opioid Manag. 2017;13(6):391-396.

24. Huber E, Robinson RC, Noe CE, van Ness O. Who benefits from chronic opioid therapy? Rethinking the question of opioid misuse risk. Healthcare. 2016;4(2):29-11. 


\section{Supplementary materials}

\section{Opioid Dose Changes Online Survey}

\section{SCREENING}

As with any research survey, there are certain criteria that must be met in order to qualify. Please answer the following screening questions, which should take no more than 2 minutes.

S1 Are you currently being treated by a medical professional for chronic pain?

Chronic pain is defined as any moderate to severe pain that lasts for 3 months or longer. It may be triggered by a disease or injury, or the cause may not be clear.
1. Yes
[CONTINUE]
2. No
[TERMINATE]
3. Not sure
[TERMINATE]

S2 How long have you been going to the medical professional who is currently managing your chronic pain?
1. $0-6$ months
[TERMINATE]
2. 7 months -1 year
[CONTINUE]
3. Longer than 1 year
[CONTINUE]

S3 Are you currently being prescribed any medications to manage your chronic pain?
1. Yes
[CONTINUE]
2. No
[TERMINATE]
3. Not sure
[TERMINATE]

S4 Are you currently being prescribed an extended-release opioid medication to manage your chronic pain? Extendedrelease is commonly abbreviated to ER and may otherwise be called Long-Acting, abbreviated to LA.
1. Yes
[CONTINUE]
2. No
[TERMINATE]
3. Not sure
[TERMINATE]

Text Unless otherwise stated, the remaining questions will focus exclusively on the extended-release/long-acting opioid medication you take to manage your chronic pain, which we will refer to as ER/LA Opioid. Please answer all questions with only ER/LA Opioid in mind - even if you are taking additional medication(s) to manage your chronic pain.

S5 Approximately how long have you been taking ER/LA Opioid?
1. $0-6$ months
[TERMINATE]
2. 7 months -1 year
[CONTINUE]
3. Longer than 1 year
[CONTINUE]

S6 To the best of your knowledge, has the medical professional managing your chronic pain made any of the following changes to your prescription of ER/LA Opioid during the past 6 months?

1. Decreased the total daily dose of $\mathbf{E R / L A}$ Opioid *

[CONTINUE]

2. Increased the total daily dose of $\mathbf{E R / L A}$ Opioid *

[CONTINUE]

3. Both increased and decreased the total daily dose of ER/LA Opioid * [TERMINATE]

4. There has been no change to my prescription of ER/LA Opioid

[CONTINUE]

5. None of the above

[TERMINATE]

6. Not sure

[TERMINATE]

* This could pertain to the number of doses of ER/LA Opioid you take each day, or the strength of each dose of ER/ LA Opioid. 
S7 Are you also currently being prescribed an immediate-release opioid medication alongside $\mathbf{E R / L A} \boldsymbol{O}$ pioid to manage your chronic pain? Immediate-release is commonly abbreviated to IR and your health care professional may refer to it as an opioid to help with "breakthrough pain".
1. Yes
[CONTINUE]
2. No
[CONTINUE]
3. Not sure
[TERMINATE]

S8 [ASK IF S7 = 1] To the best of your knowledge, has the medical professional managing your chronic pain made any of the following changes to your prescription of immediate-release opioid during the past 6 months?

1. Decreased the total daily dose of immediate-release opioid *

[CONTINUE]

2. Increased the total daily dose of immediate-release opioid *

[CONTINUE]

3. Both increased and decreased the total daily dose of immediate-release opioid *

[TERMINATE]

4. There has been no change to my prescription of immediate-release opioid

[CONTINUE]

5. None of the above

[TERMINATE]

6. Not sure

[TERMINATE]

* This could pertain to the number of doses of immediate-release opioid you take each day, or the strength of each dose of immediate-release opioid.

Text IF TERMINATED: We're sorry, but this survey requires that we recruit people that fit a different profile. Thank you for your time.

IF QUALIFY: Thank you for completing these screening questions. Based on your answers to the screening questions, you have qualified.

Please click on the "Next" button to begin the survey.

\section{QUESTIONNAIRE}

Q1 In the past 6 months, how has your level of pain when taking $\mathbf{E R / L A}$ Opioid changed, if at all?

1. Significantly worse

2. Slightly worse

3. No change

4. Slightly better

5. Significantly better

Q2 In the past 6 months, have you added any new medications or substances to your regular (every day or nearly every day) medication routine to help relieve your pain? These could include, but are not limited to, new prescription medications, over-the-counter medications, or other pain relievers.

1. Yes

2. No

Q3 In the past 6 months, how has your overall level of function when taking $\boldsymbol{E R / L A}$ Opioid changed, if at all?

Function is loosely defined as the ability to live your life as you would want to live it. High function means you are mobile and can engage in all the activities that you would be able to if you did not have chronic pain. Low function means you are less mobile and cannot engage in activities you would like to.

1. Significantly worse

2. Slightly worse

3. No change

4. Slightly better

5. Significantly better 
Q4 In the past 6 months, how has your ability to work changed, if at all?

1. Significantly worse

2. Slightly worse

3. No change

4. Slightly better

5. Significantly better

6. Non-applicable (e.g., retired)

Q5 In the past 6 months, how has your relationship with the medical professional who prescribes you ER/LA Opioid changed, if at all?

1. Significantly worse

2. Slightly worse

3. No change

4. Slightly better

5. Significantly better

Q6 In the past 6 months, how have your relationships with your friends and family changed, if at all?

1. Significantly worse

2. Slightly worse

3. No change

4. Slightly better

5. Significantly better

Q7 In the past 6 months, how has the frequency with which you experience the following side effects changed, if at all? If you do not experience the side effect, please select "Non-applicable".

\begin{tabular}{|l|l|l|l|l|l|l|}
\hline Side Effect & $\begin{array}{l}\text { Much more } \\
\text { frequently }\end{array}$ & $\begin{array}{l}\text { Slightly more } \\
\text { frequently }\end{array}$ & No change & $\begin{array}{l}\text { Slightly less } \\
\text { frequently }\end{array}$ & $\begin{array}{l}\text { Much less } \\
\text { frequently }\end{array}$ & Non-applicable \\
\hline Nausea & & & & & & \\
\hline Headache & & & & & & \\
\hline Constipation & & & & & & \\
\hline Drowsiness & & & & & & \\
\hline Itching & & & & & & \\
\hline Vomiting & & & & & & \\
\hline Dizziness & & & & & & \\
\hline Restlessness & & & & & & \\
\hline Teary eyes & & & & & & \\
\hline Runny nose & & & & & & \\
\hline Yawning & & & & & & \\
\hline Sweating & & & & & & \\
\hline Chills & & & & & & \\
\hline Muscle pain & & & & & & \\
\hline Dilated pupils & & & & & & \\
\hline
\end{tabular}

Q8 In the past 6 months, how has your overall mental health changed, if at all?

1. Significantly worse

2. Slightly worse

3. No change

4. Slightly better

5. Significantly better

Text This concludes our survey. Thank you very much for sharing your time and opinions with us!

Note: Some text appears bold or underlined for emphasis. 
The Journal of Pain Research is an international, peer reviewed, open access, online journal that welcomes laboratory and clinical findings in the fields of pain research and the prevention and management of pain. Original research, reviews, symposium reports, hypothesis formation and commentaries are all considered for publication
The manuscript management system is completely online and includes a very quick and fair peer-review system, which is all easy to use. Visit http://www.dovepress.com/testimonials.php to read real quotes from published authors.

Submit your manuscript here: https://www.dovepress.com/journal-of-pain-research-journal 